Vol. 8, Issue 8, August 2021

DOI: $10.17148 /$ IARJSET.2021.8836

\title{
Understanding Organizational Behavior in relation to work ethics and values
}

\author{
Trishna Moni Gogoi \\ Research Scholar, Department of Sociology, Dibrugarh University, Assam
}

\begin{abstract}
Globalization, technology advancement, open market system and desire of human beings to excel in every field of their work, has increased the level of competition and result into work stress. Management of human behavior and leading it into the correct direction has become important. Studying human behavior in a work setting or within an organization has considered being the most essential, as without a proper workforce structure the organization cannot work and survive. This paper tries to focus the need and importance of organizational behavior in relation to work values. It studies the challenges and opportunities face by managers to use organizational behavior concepts in a work setting. Organizational behavior is a field of study that investigates the impact of those individuals; groups and organizational structure have on behavior within the organization, for the purpose of applying such knowledge towards improving an organizational effectiveness. The key element in organizational behavior is people, structure, technology and environment. Learning and understanding organizational behavior is important because it systematically studies the application of knowledge about how human and groups act within the organization they work. The values and ethics are the moral codes by which an organization operates. It is what the organization perceives to be important regarding the behavior of its members. Members working in an organization is influenced by the organization itself and organization is influenced by its members.
\end{abstract}

Keywords: organizational behavior, human behavior, ethics and values, work environment

\section{INTRODUCTION:}

Working in a healthy environment is the basic criteria that every organization needs to fulfill about the workers. Application of motivational theories, art of leadership and skill of redesigning jobs and modification to organizational structure is an ongoing process that facilitates positive work environment leading to increased job satisfaction of employees, greater productivity and organizational growth. Due to scientific advancement managing human resources is more challenging. ( Kondalkar, 2007 ). The understanding of a group behavior in an organizational environment is a managerial task _ a task that involves the capacity to "understand" the behavior patterns of individuals, groups and organizations, to "predict" what behavioral responses will be elicited by various managerial actions and finally to use this understanding and these predictions to achieve "control". ( Saravanakumar, 2019).

Employees are one of the primary and basic assets of an organization to work. To define Organization, Amitai Etzioni says that, "Organization is a social units or human groupings deliberately constructed and reconstructed to seek specific goals." Another definition by Stephen P. Robbins and T.A. Judge is "Organization is a consciously co-ordinate social unit composed of two or more people that functions on a relatively continuous basis to achieve a common goal or set of goals."

Organizations are social systems. In today's competitive world, the organizations have to be dynamic and growth-oriented. By keeping the situations and behaviors of the workers in mind, here the study of organizational behavior has become important. Study and understanding of Organizational behavior is very interesting and challenging as well. It relates to study of individuals working together in an environment. "Organizational behavior is a field of study that investigates the impact that individuals, groups and organizational structure have on behavior within the organization, for the purpose of applying such knowledge towards improving an organizational effectiveness". It is concerned with people's thoughts, feelings, emotions, and actions in a work setting. It is the study of human behavior in an organization setting. Organizational behavior concern with the work related behavior. It work as a motivation, personality development, attitude and aptitude, job satisfaction, creating positivity, reducing stress , developing productivity and many more related to working environment among the workers. The field of the organizational behavior attempts to gather information regarding an issue in a scientific manner under controlled conditions. Therefore, organizational behavior is a comprehensive field of study in which individual, group and organizational structure is studied in relation to organizational growth and organizational culture, in an environment where impact of modern technology is great. ( Kondalkar, 2007 ). The study of Organization behavior has its roots in the late 1920s. It was started with the launch of a famous series of studies of the behavior of workers at the Hawthrone Works plant in Cicero, Illinois. (Kopp, Boyle, 2021). 


\title{
International Advanced Research Journal in Science, Engineering and Technology
}

\author{
Vol. 8, Issue 8, August 2021
}

\section{DOI: 10.17148/IARJSET.2021.8836}

Organizational Behavior is an applied behavioral science that is built on contribution from a number of other behavioral disciplines like psychology, sociology, social psychology, anthropology and political science. In this paper, effort has been made to understand the organizational behavior in relation to work ethics and values. Strong work ethics in the organization is the key to the ethical behavior of employees. Work ethics and values guide an individual way of working in a work setting. It regulates a behavior. It instructs a person what to follow and not to follow. It is the moral code of any organization that its members maintain. It includes honesty, accountability, respect, caring, reliability, peace and success. It should be define by some laws, mission and vision statement and policies. (Leonard, 2019 ).

This paper aims to study about two specific objectives. Firstly, to study the need and importance of organizational behavior in relation to work values and ethics. Secondly, to understand the challenges and opportunities face by managers in an organization.

\section{METHODOLOGY:}

The present study has been done with the help of secondary sources. It has been conducted through observing and studying various articles, books, journals, newspapers and authentic websites.

\section{DISCUSSIONS:}

3.1 Organizational behavior in relation to work ethics and values:

Work ethics are considered to be vital for achieving goals. It gives strength, positivity and right mindset. People who possess a strong work ethic are guided by some principles which regulates and mould them in a way that they can do quality work, results into better productivity. It is a kind of fuel that motivates them to work productively and to achieve their needs and goals. It is also a matter of self respect, satisfaction and fulfillment. It is based on hard work and diligence. It is a belief in the moral benefit of work. Max Weber, a German sociologist, in his work "Protestant ethic and the spirit of capitalism" has mentioned about the importance of work culture to develop the economy of a society. He focused on the ethics of work that could bring development among people. He compared religion with economy and hence said that working could help a man to achieve salvation and a man must engage himself in hard work, considering work as a virtue. With work ethics a worker perform his job efficiently. It has been the backbone of success for centuries.

Organization behavior is a kind of tool that measures the level of persistence and transparency among the workers. As a workplace ethic, an organization needs to retain and nurture talents. It is the responsibility of the organization to train the individual and make him/her aware of the policies, rules and regulations and code of conduct of the organization. (Juneja, 2015).

Ethics are the most critical issues faced by organizations. High profile scandals (e.g., Johnson \& Johnson, Boeing, Uber and Volkswagen) have highlighted the need for organizations to emphasize ethics, motivate ethical employee behavior, and reduce unethical acts. The unfortunate reality is that business reports, such as survey findings from PricewaterhouseCoopers (PwC, 2018), suggest that unethical behavior in organization are prevalent. The Association of Certified Fraud Examiners (ACFE, 2018) reported that unethical behavior is extremely costly, losses millions of dollars, reduced employee motivation and increased employees' stress. (Mitchell, 2019). Thus, in the absence of strong work ethics, employees would find it difficult and uncomfortable to achieve goals and survive.

Organizational behavior can change workers behavior and perception by developing strong work ethics and values among the employees. There are number of advantages like:-

- Better productivity

- Success achievement

- $\quad$ Flexible working environment

- Smooth decisions and policies

- Encourage changes

- Increase company's brand value

- Develops team spirit

Furthermore, apart from the above discussion, managers involved in Organizational behavior should have welcomed the cultural diversity in the organization. Due to which the diverse nature invite people from every culture, origin and trait. Organization will make it possible for all employees to feel engaged with their work and remain productive members of the organization. ( Bauer, Erdogan, 2012).

3.2 Challenges and opportunities:

Organization is a formal structure and all departments have to function in a coordinated manner to achieve the organizational objective. ( Kondalkar, 2007 ). Max Weber's concept of Bureaucracy can be applied here to understand the role of every person, from top to bottom, in an administrative structure. Everyone in the organization should work accordingly to their roles and duties, only then it can succeed and grow into a successful organization. Again, Emile 


\title{
International Advanced Research Journal in Science, Engineering and Technology
}

\author{
Vol. 8, Issue 8, August 2021
}

\section{DOI: $10.17148 / I A R J S E T .2021 .8836$}

Durkheim's ideas on Division of Labour and Specialization are very essential to an organization to be worked. Work will be divided on the basis of skill and specialization which resultant into proper and assemble production with better quality and thus fast production. It is important for all the workers to have a positive attitude towards work and work accordingly to achieve the organizational goal. On the other hand, it is also important for the manager to develop an appropriate working environment and create a work culture in the organization so that the employees could work with full plan and dedications. Therefore, it is the art on the part of manager to understand, describe, forecast and modify individual behavior.

The era, 21st century, is a challenging one. This is the era of rapid changes and development. The economies all around the world, with just a handful of expectations, are now working together and are intertwined like never before. With this, it can be observed that organizations have to adapt to the changing environment both internally and externally. An organization while maintaining its productivity with employee's relation, face challenges and opportunities. This challenges and opportunities are massive in nature and changes frequently in order to meet the business goal. Management of organization is bound to cope up with the challenges and opportunities. The challenges and opportunities of Organizational Behavior are categorized into the followings:-

- Demographic factors: one of the most challenging factors for an organization is to manage a diverse workforce. Due to globalization and liberal policies, people from any corner come and join different organization to work. This creates heterogeneity in the workplace in terms of gender, religion, race, ethnicity, age. The manager should capable to deal with people of every nature. It should be fair and justice. Providing equality irrespective of their group is the basic duty of the organization. It a challenging task for the organization to utilize the attitudes and perspectives of people from different background to improve the decision making and the performance of the organization. Moreover, there is also a flexibility challenge to the organization. The diverse nature of the organization need to be very sensitive and careful about the various kinds of employees working together in the organization. To be successful in such a diverse working environment, one must value and respect the cultures and behavior.

- $\quad$ Improving people skills: The technology, structure, environment are changing at a faster rate in the business and economic field. Until and unless the employees and executive are adaptable to such changes and equipped with the required skills, the targeted goals cannot be achieved in time.

- $\quad$ Social responsibility and ethics: The complexities and over burden of working environment has suffered the employees and force them to face ethical dilemmas. Certain situations make them question what is right and wrong and put them into a state of confusion to decide the moral code of ethic in order to complete their assign task. It has becoming challenging to differentiate right things from wrong behavior. In such situations, managers must evolve code of ethics to guide the employees through ethical dilemmas by organizing trainings, workshops, seminars.

- Globalization: Today the globalization of world business is increasing at a speedy rate. The operation of a business is not limited to one location. They are performed internationally. It is the process of economic integration at the international level. The world market system has transformed the globe into a small village. Multinational companies are having their branches in almost every nation. In this respect, the most critical component is the human resource. It is extremely difficult to get the requisite competence due to high competition to acquire that. Globalization is no doubt that it creates multiple advantages to the market system, but it has some threats also to an organization. It led to the failure of local business, different impact on culture, ethics and values and customers. Globalization affects the managerial task. The manager has to manage the workforce as they are likely to have different attitudes, perceptions, needs, behaviors and culture of their origin.

- Enhancing quality and productivity: every organization should be more quality oriented to increase its customer base. It is the main factor which affects the customer satisfaction level. Better quality products can attract more customers. It is a challenging task for the organization to collect knowledge on customer's taste of preference and thus produce products as per their satisfaction level. The organization should also keep in mind with the demand and supply of the products for which the workers/employees should work efficiently.

- $\quad$ Empowering people: empowerment of the employees is another challenging task for the organization managerial department. Excess rules and over strict nature can demoralize the employees. The organization should motivate the employees, supervise and guide them with basic techniques so that they can work with a pleasant mental condition. Moreover, less rigidity and over flexible nature can also brought losses to the organization. Thus it is a challenging task for the organization to maintain the balance.

Apart from the above discussion factors, there are some other factors also where the organization can face challenges and opportunities such as adopting new technologies, managing stress and conflict among the employees, stimulating innovation and change, improving customer service and responding to outsources.

\section{CONCLUSION:}

Organizational behavior is concerned with the characteristics and behaviors of employees. The principles of the study of organizational behavior are to apply primarily in attempting to make the business work more efficiently. In conclusion it can be said that appropriate work ethics and values can grow the organization and help it to achieve the 


\section{International Advanced Research Journal in Science, Engineering and Technology}

Vol. 8, Issue 8, August 2021

DOI: 10.17148/IARJSET.2021.8836

targeted goal. Work ethics and values act as a moral tool that guides the employees. However, there is a part to play from the managerial desk too in terms with setting ethics and values. The managerial ground must be flexible as there are employees from different backgrounds. Ethics and values are should be such that it encourages empowerment. Although there are both challenges and opportunities for an organization, but with proper planning and decision it can be faced and achieved respectively. Therefore, an organization behavior is very important for understanding the human behavior of the organization working there to make progress in the business and economic field.

\section{REFERENCES:}

1. Abraham, F. Morgan, J.H. "Sociological thought", Macmillan Publishers India Ltd. 1985

2. Bauer, T and Erdogan, B. "An Introduction to Organizational Behavior", (http://lardbucket.org) December, $29,2012$.

3. Brief, A.P and Weiss, H.M, “ Organizational Behavior: Affect in the work place”, Annu. Rev. Psychol. 2002. 53:279-307.

4. Etzioni, A. "Modern Organizations", Prentice- Hall of India Private Limited, New Delhi (India), $1^{\text {st }}$ Indian edition, 1965.

5. Frederick, P.R.H, "Organization Behavior and its Role in Management of Business", Global Journal of Finance and Management, ISSN 0975-6477 vol. 6, 2014.

6. Gade, P, "Challenges of Organizational Behavior” (https://www.academia.edu/4487193)

7. Juneja, P. "Importance of Workplace Ethics" ManagementStudyGuide.com

8. Kast, F.E. and J.E. Rosenweing, "Organization and Management", McGraw-Hill New York, 1979

9. Kendalkar, V.G, “Organizational behavior”, New Age International Publishers, 2017.

10. Kharka, S.S, “Organizational Behavior", Chand and Company Ltd., New Delhi- 110055, 2004.

11. Kreitner, R and Kinicki, A. "Organizational Behavior”. Third Edition, Chicago; Irwin (1995).

12. Luthans, F. "Organizational Behavior", McGraw Hills, International Edition, 7th Edition, 1995.

13. Mitchell, M.S and et.al. "The study of behavioral ethics within organizations: A special issue introduction", Personnel Psychology Wiley, DOI: 10.1111/peps.12381, 2019.

14. Panigrahi, S.K and Al-Nashash, H.M, "Quality Work Ethics and Job Satisfaction: An Empirical Analysis", Quality- Access to Success, 20(168): 41-47, DOI: 10.2139/ssrn.3515072.

15. Saravanakumar,A, “OrganizationalBehavior”,https://www.researchgate.net/publication/330409514, January, 2019

16. Sekaran, U. "Organizational Behavior" Text and Cases, Tata McGrow Hill, New Delhi

17. Sharma, N. “ Organizational Behavior: Challenges and Opportunities”, IOSR Journal of Business And Management (IOSR- JBM), eISSN: 2278-487X, p-ISSN: 2319-7668. Vol.20. 2018

18. Sharma, R.A. “Organizational Theory and Behavior”, Tata McGraw Hill. Publishing Co. Ltd., New Delhi 